\title{
J. S. HALDANE CENTENARY, 1961
}

The Physiological Society has recently commemorated the centenary of the birth of John Scott Haldane in 1860, by organizing a symposium and by devoting the first day of their meeting to papers on his pioneer work and subsequent developments. These were held at Oxford on July 24-29, 1961 : nearly every respiratory physiologist of world renown was able to be present.

Haldane's additions to knowledge were mainly in the field of respiration and its regulation: this, however, is closely connected with the regulation of the circulation, and neither can be of maximum use to the body without the other. He was a pioneer also in the study of acclimatization to the low $\mathrm{O}_{2}$ pressure of high altitudes, and the adaptation of the subject with cyanotic congenital heart disease is in many ways the same, since it too is mainly the reaction to low $\mathrm{O}_{2}$ pressure. These two aspects make the questions discussed of special interest to cardiologists apart from the intrinsic interest and importance of all his work.

Haldane would have been the first to admit that the time was ripe for great advances, but without his widespread activities and his grasp of the subject as a whole, it is doubtful if such simple concepts about the regulation of the breathing would have been reached-concepts that have lasted with little change for so long. He would have wished also that the names of many others should be mentioned -both those who worked with him and those who worked at other centres-especially August Krogh of Copenhagen, Joseph Barcroft of Cambridge, and C. G. Douglas of Oxford. Douglas was fortunately able to attend and received an especially warm welcome when he took the chair at the opening of the symposium.

\section{MONDAY AND TUESDAY: NORMAL CONTROL OF RESPIRATION}

After the chairman of the symposium C. G. Douglas had given his opening address, the first two days were given to papers on the physiological control of respiration. The relative roles of $\mathrm{CO}_{2}$, lack of $\mathrm{O}_{2}$, and nervous impulses were discussed, and also the part played by peripheral and central receptors, especially chemo-receptors. A great deal has been learnt in detail since Haldane's work but agreement about how exactly these different factors are co-ordinated in the control of the respiration does not seem to have been reached.

Among many papers of interest, only a few can be mentioned. B. B. Lloyd and D. J. C. Cunningham, who had been the main organizer of the symposium, put forward a quantitative exposition of the relationships between pulmonary ventilation, the alveolar gas pressures, and other factors such as temperature, noradrenaline, and metabolic acidæmia. These were expressed in a relatively simple algebraical formula which fitted in with many of their data. A. Crapton Smith and J. M. K. Spalding showed, however, that in patients who had earlier needed artificial ventilation for several weeks with positive pressure regulation, spontaneous ventilation was affected for some time by the rhythm of this.

E. Neil described his observations on the chemosensory terminals of the 9th nerve in the cells of the carotid body. They are excited when these cells are exposed to a fall in their tissue $\mathrm{pO}_{2}$. This does not happen easily because of their fantastically large blood supply. E. Witzler (Germany) presented different views on this subject. 
There was an excellent discussion on the brain stem centres that are sensitive to $\mathrm{CO}_{2}$. This had been co-ordinated in advance by the speakers and was followed by a lively discussion. The concepts presented here, by Dr. E. Leusen (Ghent), L. D. Robin (Pittsburg), S. Semple (London), H. Loeschcke (Göttingen), and C. Lambertsen (Philadelphia), that $\mathrm{pH}$, or something closely related to it, in the C.S.F. controls respiration, and that blood $\mathrm{pCO}_{2}$ is the dominant factor in adjusting C.S.F. $\mathrm{pH}$, were an exciting extension of previously held views on the nature of the control response to $\mathrm{CO}_{2}$. In retrospect, Haldane's views on the subject expressed before the first World War have a surprisingly modern ring.

H. Rahn's (Buffalo, N.Y.) contribution on breath holding and "skin diving" deserves mention, because it was so much in the Haldane tradition of elucidating complex situations with simple apparatus and clear thought.

H. de B. Daly and M. J. Scott described their work on the influence of breathing low $\mathrm{O}_{2}$ mixtures on increasing the heart rate and cardiac output. Reflexes from the carotid body chemo-receptors, which by themselves produce bradycardia, were changed by the increased pulmonary ventilation, with the result that tachycardia replaced the directly induced bradycardia.

It would be interesting to know if this relationship of ventilation and cardiac activity is present in the response to exercise and how the increases in both are correlated. Though there was much discussion about the increase of ventilation with exercise (see p. 713), there was little about the similar increase of cardiac output, another of Haldane's major interests. The co-ordination of ventilation with the increased demands made during exercise, especially the fact that the receptors on the arterial side continue to stimulate respiration after so much of the stimulating substances have been removed by the lungs remains an unsolved mystery. The study of the simultaneous changes in ventilation and cardiac output in patients with heart disease-especially those with cyanotic congenital heart disease who provide such natural experiments in the reaction to lack of oxygen-might throw more light on the mechanisms involved and on their relationship.

\section{Wednesday: Respiratory Adaptation to High Altitudes}

H. Chiodi from Argentina spoke of his results obtained on residents at various altitudes, from sea level up to a height of 4500 metres $\left(14,800 \mathrm{ft}\right.$.). The arterial $\mathrm{O}_{2}$ saturation falls from 96 to 83 per cent, and the arterial $\mathrm{pCO}_{2}$ from 40 to $34 \mathrm{~mm}$. $\mathrm{Hg}$, but the arterial plasma $\mathrm{pH}$ remains relatively constant. The increase in the pulmonary ventilation above that at sea level is already 16 per cent at $2000 \mathrm{~m}$. and 26 per cent at $3000 \mathrm{~m}$. (10,000 ft.), but does not increase greatly after this. Breathing pure $\mathrm{O}_{2}$ shows that the chemo-receptors are more active between 2000 and $3000 \mathrm{~m}$., but in no case does it bring the ventilation back to sea-level values. He concluded that the increased ventilation can not be explained entirely by changes in arterial $\mathrm{pO}_{2}$ or in the sensitivity of the respiratory centre to $\mathrm{CO}_{2}$ and that there must be other regulating factors. His results on the natives at high altitudes differed in some respects from the speakers who had studied visitors only.

R. H. Kellogg of California pointed out that hyperventilation, due to hypoxic stimulation of the chemo-receptors, is the most important early adaptation to altitude, but it lowers the $\mathrm{pCO}_{2}$ level. The regulatory mechanism is progressively reset so that it becomes sensitive to lower levels of $\mathrm{pCO}_{2}$. $\mathrm{He}$ concluded that the changes in the level at which $\mathrm{pCO}_{2}$ stimulated the respiration played the major role in the early stages of acclimatization; but that the mechanism remained obscure.

J. S. Milledge (with L. G. C. E. Pugh) spoke of the results of the recent British expedition to the Ama Dablam glacier in the Himalayas. Physiological equipment had been set up at 17,000 ft. and some at 19,000 ft. $(6000 \mathrm{~m}$.), and several members had lived for some months at these heights so that their adaptation could be studied. By applying the techniques that had been developed at Oxford, they showed that the main regulatory changes to acclimatization are confined to the response to $\mathrm{CO}_{2}$, the response to hypoxia remaining largely unchanged. Only a part of the changed $\mathrm{CO}_{2}$ response is explained by the acid-base changes in the blood and other chemical changes, perhaps in the cerebro-spinal fluid, need investigation. 
After these, two unrelated papers were read. C. Liljestrand and his colleagues from Stockholm found that passive tilting from supine to standing position quickly led to a fall in blood pressure, increased ventilation, a lowering of the end-tidal $\mathrm{CO}_{2}$ pressure, and an increased arterial $\mathrm{pH}$, with the usual rise of pulse rate. These changes tended to revert to the previous levels in orthostatically stable subjects, but not in the unstable, where they might progress till the subject fainted. On tilting back to the supine position, the reverse changes were observed and again there was some overshoot.

J. B. S. Haldane (with Helen Spurway) spoke of the regulation of breathing in a tropical fish that lived in rather muddy pools, spending most of its time on the bottom, but ascending for a breath of air which it swallowed and held in the pharynx. These ascents are extremely regular if the water is fairly de-oxygenated. On substituting oxygen for air above the water, the time between ascents is lengthened from 4 to 16 minutes. Low $\mathrm{O}_{2}$ pressures reduce the time between ascents from 4 to about 1 minute. These simple experiments, developed from his father's 19 th century work on man, again yielded clear and interesting results.

\section{ThuRSDAY: THE HYPERPNGA OF EXERCISE}

F. F. Kao of New York described his cross-circulation experiments in dogs to identify the neural and humoral pathways involved in exercise hyperpnœa. All data supported (1) the hypothesis of the exercise stimulus being generated in the working muscles, and (2) the existence of a respiratory chemostat that responds to arterial $\mathrm{pCO}_{2}, \mathrm{pH}$, and $\mathrm{pO}_{2}$, and of an additional neural mechanism for the regulation of respiration in exercice. There is no evidence for the existence of pulmonary chemo-receptors that are responsive to humoral agents released from exercising muscles.

M. Nielson and E. Asmussen of Copenhagen, from experiments where the circulation from the working muscles was interrupted by the means of pneumatic cuffs, thought that the neural mechanism is more important. Other speakers expressed some doubt as to whether the circulation had been completely interrupted.

P. O. Åstrand and E. H. Christensen of Stockholm thought that the small difference in ventilation in the first ten seconds of starting light and very heavy work shows that the nervous factors are not important in regulating the quantity of the change though they may be in initiating it. The findings at the end of exercise are similar. Experiments made during heavy work show that maximal $\mathrm{O}_{2}$ intake is not limited primarily by the ventilatory capacity.

R. L. Riley from Baltimore showed an ingenious four-quadrant diagram in which the most constant relationship is between the ventilation and the systemic venous $\mathrm{pCO}_{2}$. The effective chemo-receptors should, therefore, be looked for in the systemic venous or pulmonary arterial systems. Some speakers thought this constant relationship was no more than an inevitable consequence of the more generally accepted relationships shown in the other three quadrants.

P. Dejours of Paris thought that both nervous and humoral factors must be involved, and that they are of different importance in the very different types of exercise that can be taken. For example, in an easy dynamic exercise such as walking, neurogenic stimuli provoke an immediate increase in ventilation; humoral stimuli intervene more slowly; and finally both stimuli determine a steady state of hyperventilation. Similar changes occur when the exercise is stopped.

D. B. Dill of Bloomington, Indiana, reported how his ventilatory capacity and oxygen uptake with exercise had declined over the years. The rate at which $\mathrm{O}_{2}$ could be supplied to the tissues during exercise declined by one quarter from 16 to 45 years, and by nearly one half from 16 to 68 years of age.

During the afternoon, papers on various other aspects of respiration were read, but unfortunately I was not able to be present.

Friday: Papers on Various Aspects of the Work of J. S. Haldane

C. G. Douglas gave an Introductory Address. Haldane's work was a closely-knit mixture of pure 
and applied physiology. He had not changed from one to the other, but throughout his life moved freely from the laboratory to the coal mine, and from the factory back to the laboratory, making his discoveries in one sphere illuminate the other. Thus, for example, the investigation of the atmosphere of stuffy and unhygienic rooms and factories pointed to the possible role of $\mathrm{CO}_{2}$ as the main factor controlling the breathing; and his knowledge of the high metabolic exchange of small animals led to his introduction of mice and canaries into the coal mines, as the only test for dangerous amounts of carbon monoxide that could be used easily by relatively untrained men. He is the only physiologist who has been President of the Institution of Mining Engineers.

Haldane's experiments and conclusions generally had the virtue of simplicity, even in subjects that had seemed very complex before. His methods and apparatus too were generally simple and some have been used in most parts of the world for many decades-his hæmoglobinometer, his gasanalysis apparatus, and (if we may include his collaborators) the Douglas bag. Provided the apparatus gave reliable results, Haldane spent no more time on making it less bulky or less fatiguing to use: such improvements were generally added by others but the fundamental simplicity remained.

F. J. W. Roughton of Cambridge spoke on The Chemistry of Respiration. Here a good deal more has been settled about the role of myoglobin in muscle and about the oxyhæmoglobin dissociation curve and the way in which it is influenced by $\mathrm{CO}_{2}$. He finished with a quotation from Barcroft expressing warm appreciation of Haldane's work, which showed how they felt about each other in spite of the many battles they had waged.

J. H. Comroe of San Francisco spoke of Pulmonary Gas Exchange. He agreed that Haldane's view of the secretion of $\mathrm{O}_{2}$ by the alveoli had not proved correct (many of Haldane's pupils did not accept this aspect, even at the time). He had found, however, that the alveolar cells did excrete a substance that had remarkable effects on the surface tension and helped in the gaseous exchange and in preventing collapse of the lungs.

E. Asmussen of Copenhagen spoke on the Regulation of Respiration, and tried to draw some firm conclusions from the various facts that had been brought forward. The pressure of $\mathrm{CO}_{2}$, the depression of $\mathrm{O}_{2}$ below a certain level, and nervous reflexes are all important factors, but the exact way in which their influences are correlated is not yet clear.

A. Hurtado of Peru spoke on Altitude. After summarizing some of the work that has been done since Haldane's expeditions to Pike's Peak and elsewhere, he emphasized the great difference that is found between the relative newcomer who is developing his acclimatization, even after a residence of many months, and the Indian inhabitant who has lived there all his life and has a more perfect adaptation. Without seeing his paper after publication, ${ }^{*}$ I can not make any useful comparison between these men and the patients with cyanotic congenital heart disease.

In the afternoon, C. G. G. Damant (in absence) and K. W. Donald spoke on Applied Physiology in the Armed Forces with special reference to Diving. After paying tribute to both Haldane and his son as pioneers in this subject, he described Haldane's brilliant investigations into the hazards of air diving at the beginning of the century. In a few years he developed the stage decompression system which largely solved the problem of decompression sickness. He also demonstrated and remedied $\mathrm{CO}_{2}$ narcosis caused by inadequate helmet ventilation.

Donald then reviewed work carried out by Haldane on $\mathrm{O}_{2}$ poisoning, submarine escape, the development of independent divers, and the use of nitrogen/oxygen mixtures to avoid the hazards of $\mathrm{O}_{2}$ poisoning. He showed how this early and imaginative work allowed others to develop rapidly suits and apparatus for a whole variety of complex operational tasks in the second world war.

R. Passmore of Edinburgh spoke of Applied Physiology in Industry with special reference to Mining. He described some of the work that had been done in preventing the risks of explosions, but many of Haldane's methods for detecting these risks are still in use. He paid one of the most striking tributes to Haldane's work when he said that he had started in the mines 18 years after

\footnotetext{
* Papers are to be published in a single volume by Blackwall Scientific Publications, Oxford, towards the end of the year.
} 
Haldane's death; yet he had rarely met a mining engineer who was not familiar with Haldane's work and had met many miners who still remembered him.

J. B. S. Haldane spoke on A possible development of J.S. Haldane's Views on the Relation between Quantum Mechanics and Biology. The magnitudes of space and time were shown on a logarithmic scale and the relatively small parts of these that were concerned with biological processes were discussed. He put forward the idea that, in the physico-chemical sense, thought may be a quantal event which takes a long time, perhaps a second, to be completed; and that this long duration is associated with a wide extension in the space involved, a space about the size of the human brain.

For one who knew the position of respiratory physiology in 1912-22, it was interesting how much had been added without much change in the fundamental principles that had by then been established. It was stimulating to hear the differences of opinion still persisting and the frank but friendly criticisms expressed after so many of the papers.

The symposium closed with a party in Magdalen College cloisters and a dinner divided between Magdalen and University Colleges.

MAURICE CAMPBELL 